\title{
Effect of El Niño on U.S. Landfalling Hurricanes, Revisited
}

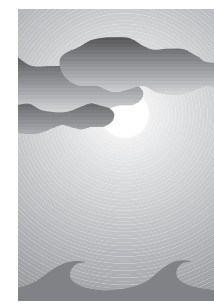

Mark C. Bove, ${ }^{*}$ James B. Elsner, ${ }^{+}$Chris W. Landsea, ${ }^{\#}$ Xufeng Niu, ${ }^{\circledR}$ and James J. O’Brien*

\begin{abstract}
Changes in the frequency of U.S. landfalling hurricanes with respect to the El Niño-Southern Oscillation (ENSO) cycle are assessed. Ninety-eight years (1900-97) of U.S. landfalling hurricanes are classified, using sea surface temperature anomaly data from the equatorial Pacific Ocean, as occurring during an El Niño (anomalously warm tropical Pacific waters), La Niña (anomalously cold tropical Pacific waters), or neither (neutral).

The mean and variance of U.S. landfalling hurricanes are determined for each ENSO phase. Each grouping is then tested for Poisson distribution using a chi-squared test. Resampling using a "bootstrap" technique is then used to determine the $5 \%$ and $95 \%$ confidence limits of the results. Last, the frequency of major U.S. landfalling hurricanes (sustained winds of $96 \mathrm{kt}$ or more) with respect to ENSO phase is assessed empirically.

The results indicated that El Niño events show a reduction in the probability of a U.S. landfalling hurricane, while La Niña shows an increase in the chance of a U.S. hurricane strike. Quantitatively, the probability of two or more landfalling U.S. hurricanes during an El Niño is $28 \%$, of two or more landfalls during neutral conditions is $48 \%$, and of two or more landfalls during La Niña is $66 \%$. The frequencies of landfalling major hurricanes show similar results. The probability of one or more major hurricane landfall during El Niño is $23 \%$ but is $58 \%$ during neutral conditions and $63 \%$ during La Niña.
\end{abstract}

\section{Introduction}

It is now well accepted that El Niño reduces hurricane activity in the Atlantic basin. Gray (1984) uses physical processes that accompany El Niño to describe reduced hurricane activity. Gray (1984) also finds that of the 54 major hurricanes striking the U.S. coast during 1900-83, only four occurred during the 16 El Niño years in contrast to 50 making landfall during the 68 non-El Niño years. This is a rate of 0.74 during non-

\footnotetext{
*Center for Ocean-Atmospheric Prediction Studies, The Florida State University, Tallahassee, Florida.

+Department of Meteorology, The Florida State University, Tallahassee, Florida.

\#Hurricane Research Division, NOAA/Atlantic Oceanographic and Meteorological Laboratories, Miami, Florida.

${ }^{\circledR}$ Department of Statistics, The Florida State University, Tallahassee, Florida.

Corresponding author address: Dr. James J. O'Brien, Center for Ocean-Atmospheric Prediction Studies, The Florida State University, Tallahassee, FL 32306-3040.

E-mail: obrien@coaps.fsu.edu

In final form 30 June 1998.

C1998 American Meteorological Society
}

El Niño years and 0.25 major hurricanes per year during El Niño events, almost a 3:1 ratio. O'Brien et al. (1996) showed that the probability of two or more hurricanes making landfall on the U.S. coast during El Niño is $21 \%$, while the probability of two or more U.S. hurricanes during neutral conditions is $46 \%$. However, the data and methodology used in O'Brien et al. (1996) work are limited.

We reanalyze the frequency of hurricanes making landfall in the United States from 1900 to 1997 for the phases of the El Niño-Southern Oscillation (ENSO). Corrected U.S. hurricane data are used, and tropical storms are not considered in this study. The reanalysis shows that during an El Niño year, the probability of two or more hurricanes making landfall in the United States is $28 \%$. The reanalysis further determines that the probability of two or more U.S. hurricanes during the other two phases is larger: $48 \%$ during neutral years and 66\% during La Niña (cold phase of ENSO). Also, we determine the range of these strike probabilities for El Niño and La Niña. Strike probabilities of major U.S. hurricanes during each ENSO phase are also considered. 


\section{What is an El Niño?}

El Niño (warm phase) involves an anomalous warming of the eastern tropical Pacific Ocean. Here we base the definition of an El Niño event on that developed by the Japan Meteorological Agency (Marine Department, Japan Meteorological Agency 1991) rather than on the Southern Oscillation index, which is relatively noisy.

The Japan Meteorological Agency (JMA) index defines El Niño events based on the sea surface temperature anomalies in the region $4^{\circ} \mathrm{N}-4^{\circ} \mathrm{S}, 150^{\circ} \mathrm{W}-$ $90^{\circ} \mathrm{W}$. An El Niño is identified when the 5-month running average of SST anomalies is greater than $0.5^{\circ} \mathrm{C}$ for at least six consecutive months. The event must begin before September and include October, November, and December.

We also examine the opposite extreme of El Niño, which is known as La Niña (cold phase or La Niña). The definition of La Niña is chosen to be symmetric to that of the El Niño. Thus, an La Niña occurs when the JMA SST index is at least $0.5^{\circ} \mathrm{C}$ below average for six consecutive months, starting before September and running through December. Years that do not meet the definition for either El Niño or La Niña are considered neutral. The classification of each year is shown in Table 1.

Extremes in the ENSO cycle typically develop during summer, peak in late fall, and decay into the following spring. Therefore, for this analysis, we choose to define an ENSO year as the calendar year in which the El Niño develops. This definition is different than the JMA definition of an ENSO year, which runs from October of the year of development to the following September. Consequently, hurricane seasons are not broken up into two separate ENSO years. For example, under the JMA definition, the hurricane season of 1982 is considered neutral from June to September (considered JMA ENSO year 1981), then El Niño for October and November (JMA ENSO year 1982). With our change, the 1982 hurricane season falls entirely within ENSO year 1982.

\section{Reasons for reanalysis}

There are three main limitations in the original work of O'Brien et al. (1996). First, the JMA definition of an ENSO year was used, which breaks up a hurricane season into two separate events, as described above. Second, the original study only used 42 years of data, which is small for determining climatological changes. To increase the sample size, O'Brien et al. (1996) used a resampling technique. This technique is known to be conservative with respect to a measure of dispersion. Thus, the probabilities concerning El Niño U.S. hurricanes have likely been conservative. Last, the data record of all U.S. hurricanes used in the original study included landfalls which never occurred. For example, the data used in O'Brien et al. (1996) showed two U.S. hurricanes during JMA ENSO year 1957 (October 1957-November 1958), when in actuality there were no U.S. hurricanes during this period.

\section{Histograms of hurricane landfall occurrence}

\section{a. All U.S. hurricanes}

The sample size for examining North Atlantic hurricanes with respect to ENSO is small, with 22 El Niño years, 22 La Niña years, and 54 neutral years. From
TABLE 1. List of ENSO years, based on the JMA-SST index. The column indicates the decade (1900-1909 shown as 190x, etc.), and the row indicates year. "W" indicates a warm phase, "C" indicates a cold phase, and " $\mathrm{N}$ " indicates neutral conditions.

\begin{tabular}{c|cccccccccc}
\hline \hline Year & $\mathbf{1 9 0 x}$ & $\mathbf{1 9 1 x}$ & $\mathbf{1 9 2 x}$ & $\mathbf{1 9 3 x}$ & $\mathbf{1 9 4 x}$ & $\mathbf{1 9 5 x}$ & $\mathbf{1 9 6 x}$ & $\mathbf{1 9 7 x}$ & $\mathbf{1 9 8 x}$ & $\mathbf{1 9 9 x}$ \\
\hline $\mathbf{0}$ & $\mathrm{N}$ & $\mathrm{C}$ & $\mathrm{N}$ & $\mathrm{W}$ & $\mathrm{W}$ & $\mathrm{N}$ & $\mathrm{N}$ & $\mathrm{C}$ & $\mathrm{N}$ & $\mathrm{N}$ \\
$\mathbf{1}$ & $\mathrm{N}$ & $\mathrm{W}$ & $\mathrm{N}$ & $\mathrm{N}$ & $\mathrm{N}$ & $\mathrm{W}$ & $\mathrm{N}$ & $\mathrm{C}$ & $\mathrm{N}$ & $\mathrm{W}$ \\
$\mathbf{2}$ & $\mathrm{W}$ & $\mathrm{N}$ & $\mathrm{C}$ & $\mathrm{N}$ & $\mathrm{C}$ & $\mathrm{N}$ & $\mathrm{N}$ & $\mathrm{W}$ & $\mathrm{W}$ & $\mathrm{N}$ \\
$\mathbf{3}$ & $\mathrm{C}$ & $\mathrm{W}$ & $\mathrm{N}$ & $\mathrm{N}$ & $\mathrm{N}$ & $\mathrm{N}$ & $\mathrm{W}$ & $\mathrm{C}$ & $\mathrm{N}$ & $\mathrm{N}$ \\
$\mathbf{4}$ & $\mathrm{W}$ & $\mathrm{N}$ & $\mathrm{C}$ & $\mathrm{N}$ & $\mathrm{C}$ & $\mathrm{C}$ & $\mathrm{C}$ & $\mathrm{N}$ & $\mathrm{N}$ & $\mathrm{N}$ \\
$\mathbf{5}$ & $\mathrm{W}$ & $\mathrm{N}$ & $\mathrm{W}$ & $\mathrm{N}$ & $\mathrm{N}$ & $\mathrm{C}$ & $\mathrm{W}$ & $\mathrm{C}$ & $\mathrm{N}$ & $\mathrm{N}$ \\
$\mathbf{6}$ & $\mathrm{C}$ & $\mathrm{C}$ & $\mathrm{N}$ & $\mathrm{N}$ & $\mathrm{N}$ & $\mathrm{C}$ & $\mathrm{N}$ & $\mathrm{W}$ & $\mathrm{W}$ & $\mathrm{N}$ \\
$\mathbf{7}$ & $\mathrm{N}$ & $\mathrm{N}$ & $\mathrm{N}$ & $\mathrm{N}$ & $\mathrm{N}$ & $\mathrm{W}$ & $\mathrm{C}$ & $\mathrm{N}$ & $\mathrm{W}$ & $\mathrm{W}$ \\
$\mathbf{8}$ & $\mathrm{C}$ & $\mathrm{W}$ & $\mathrm{N}$ & $\mathrm{C}$ & $\mathrm{N}$ & $\mathrm{N}$ & $\mathrm{N}$ & $\mathrm{N}$ & $\mathrm{C}$ & \\
$\mathbf{9}$ & $\mathrm{C}$ & $\mathrm{N}$ & $\mathrm{W}$ & $\mathrm{N}$ & $\mathrm{C}$ & $\mathrm{N}$ & $\mathrm{W}$ & $\mathrm{N}$ & $\mathrm{N}$ & \\
\hline
\end{tabular}


these years, the number of U.S. hurricanes per ENSO phase is calculated. A tropical cyclone that makes at least one landfall somewhere in the United States as a hurricane, or affects a portion of the U.S. coast with hurricane force winds, is considered a U.S. hurricane. Some U.S. hurricanes make multiple landfalls. Here we only consider the number of U.S. hurricanes, not the number of landfalls. Under this definition, the mean annual number of U.S. hurricanes during El Niño years is 1.04, 1.61 during neutral years, and 2.23 during La Niña years. The number of U.S. hurricanes for each year is shown in Table 2 .

The Poisson distribution is useful for describing rare, extreme events, such as the occurrence of hurricanes along the coastline. The Poisson distribution is characterized by the equality of the mean and variance. The ratio of the variance to the mean $(\bar{x})$ can be tested using a chi-squared $\left(\chi^{2}\right)$ distribution (Keim and Cruise 1998). Let the ratio $R=\sigma^{2} / \bar{x}$ and $N$ be the number of observations. Here $R$ is tested against a critical $R(R \mathrm{c})$ obtained from $\chi^{2}{ }_{N-1, \alpha} /(N-1)$. With $\alpha=0.10$, Table 3 shows the rest results stratified by ENSO events.

The ratios for neutral and cold events are close to unity, allowing us to assume a Poisson process (Elsner and Kara 1998; Elsner and Schmertmann 1993). Warm events are not Poisson permissible, so we adopt an empirical approach. Using these two methods, we find the probability of two or more hurricanes making U.S. landfall is $28 \%$ during El Niño, $48 \%$ during neutral years, and $66 \%$ during La Niña (Fig. 1).

The bootstrap technique (Draconis and Efron 1983) is used to determine confidence limits of U.S. hurricanes during warm and cold ENSO events. One thousand bootstrap records of U.S. hurricanes with respect to ENSO phase are created with a sample size of 22 . The mean
TABLE 2. List of U.S. hurricanes per year. The column indicates the decade (1900-1909 hown as $190 x$, etc.), the row indicates the year.

\begin{tabular}{l|cccccccccc} 
Year & $\mathbf{1 9 0 x}$ & $\mathbf{1 9 1 x}$ & $\mathbf{1 9 2 x}$ & $\mathbf{1 9 3} \mathbf{x}$ & $\mathbf{1 9 4 x}$ & $\mathbf{1 9 5 x}$ & $\mathbf{1 9 6 x}$ & $\mathbf{1 9 7} \mathbf{1 9 8 x}$ & $\mathbf{1 9 9 x}$ \\
$\mathbf{0}$ & 1 & 2 & 2 & 0 & 2 & 3 & 2 & 1 & 1 & 0 \\
$\mathbf{1}$ & 2 & 2 & 2 & 0 & 2 & 0 & 1 & 3 & 0 & 1 \\
$\mathbf{2}$ & 0 & 2 & 0 & 2 & 2 & 1 & 0 & 1 & 0 & 1 \\
$\mathbf{4}$ & 2 & 2 & 1 & 5 & 1 & 3 & 1 & 0 & 1 & 1 \\
$\mathbf{5}$ & 0 & 3 & 1 & 2 & 3 & 3 & 1 & 1 & 6 & 2 \\
$\mathbf{6}$ & 4 & 6 & 3 & 3 & 1 & 1 & 2 & 1 & 2 & 2 \\
$\mathbf{7}$ & 0 & 1 & 0 & 0 & 3 & 1 & 1 & 1 & 1 & 1 \\
$\mathbf{8}$ & 1 & 1 & 2 & 2 & 3 & 0 & 1 & 0 & 1 & \\
$\mathbf{9}$ & 4 & 1 & 2 & 1 & 3 & 3 & 2 & 3 & 3 & \\
\hline
\end{tabular}

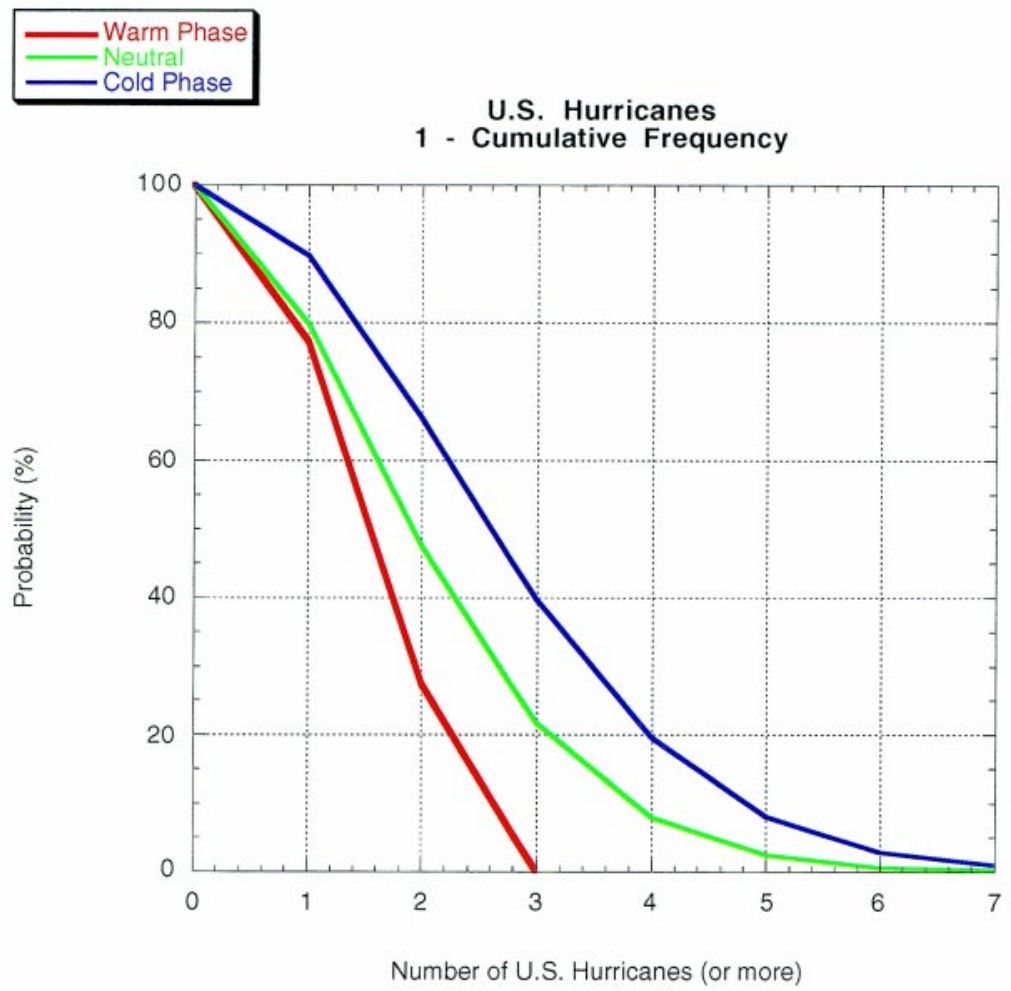

FIG. 1. Inverse cumulative frequency distributions of U.S. landfalling hurricanes, 1900-97. Red line indicates warm phase of ENSO, blue line indicates cold phase of ENSO, green line indicates neutral ENSO conditions.

and empirical frequencies for each bootstrap sample are determined, and ranked in order to produce $5 \%$ and $95 \%$ confidence limits of the ENSO event. The same 
TABLE 3. Results of Poisson tests on annual means and variances of the number of U.S. landfalling hurricanes by ENSO events.

\begin{tabular}{lcccccc}
\hline $\begin{array}{c}\text { ENSO } \\
\text { event }\end{array}$ & $\boldsymbol{N}$ & Mean & $\boldsymbol{\sigma}^{2}$ & $\boldsymbol{R}$ & $\begin{array}{c}\text { Reject } \\
\text { region }\end{array}$ & Accept? \\
\hline Neutral & 54 & 1.61 & 1.64 & 1.02 & $>1.26$ & Yes \\
Cold & 22 & 2.23 & 2.08 & 0.93 & $<0.63$ & Yes \\
Warm & 22 & 1.04 & 0.50 & 0.48 & $<0.63$ & No \\
\hline
\end{tabular}

procedure is used for both the La Niña and neutral years. In these cases the bootstrapped mean is used as the Poisson parameter.

Figure 2 a shows the $5 \%$ and $95 \%$ confidence limits of U.S. hurricanes during El Niño. During El Niño, we are 90\% confident that the probability of no hurricanes making U.S. landfall is somewhere between $17 \%$ and $24 \%$. The probability of exactly one U.S. hurricane given an El Niño is between $45 \%$ and
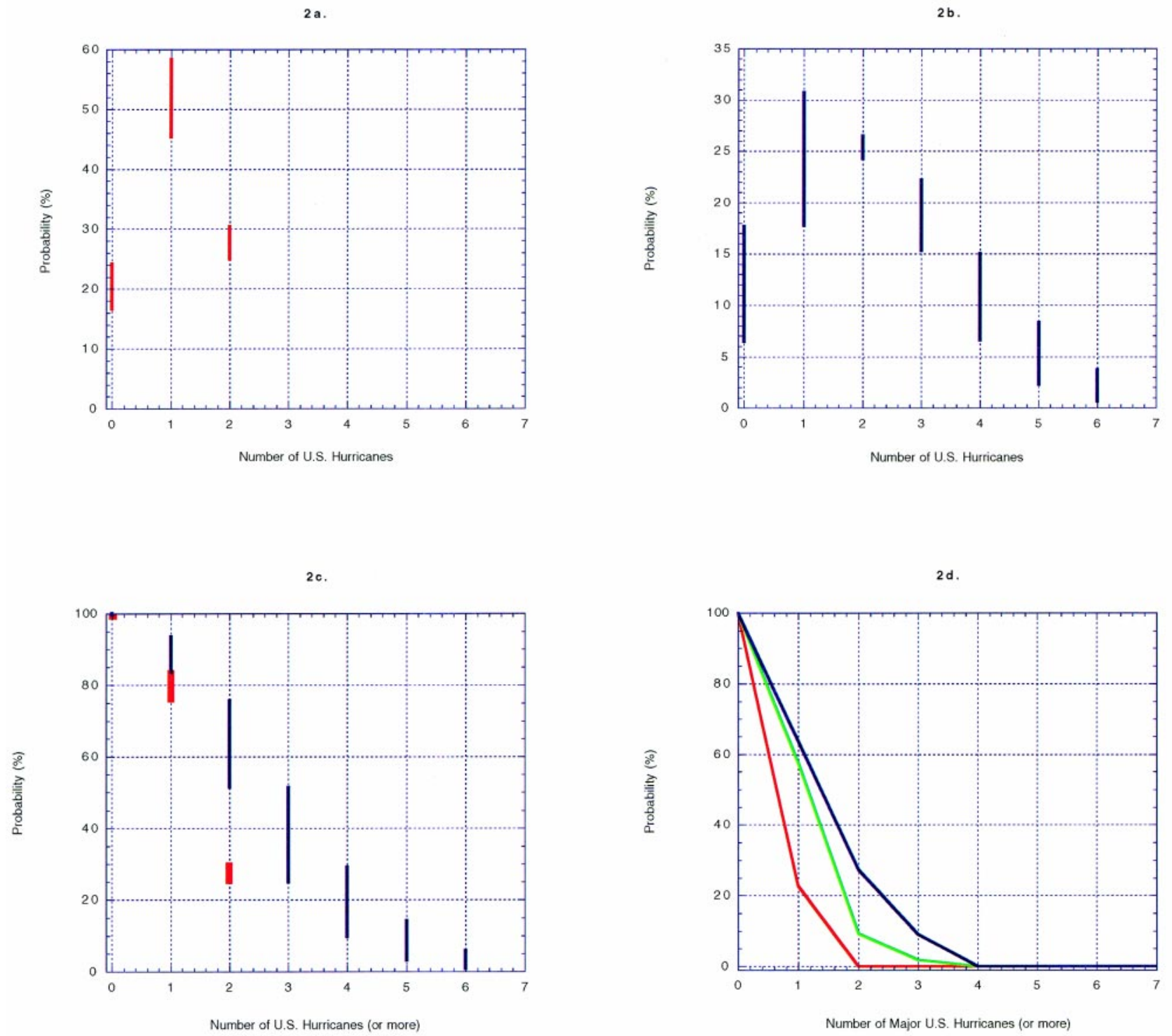

FIG. 2. (a) Probability distributions of U.S. hurricanes at the 5\% and $95 \%$ confidence levels for the ENSO warm phase. (b) Probability distributions of U.S. hurricanes at the 5\% and 95\% confidence levels for the ENSO cold phase. (c) Inverse cumulative frequency distributions of U.S. hurricanes at $5 \%$ and $95 \%$ confidence levels for warm and cold phases of ENSO. Red bars indicate warm phase, blue bars indicate cold phase. (d) Inverse cumulative frequency distributions of major U.S. hurricanes, 1900-97. Red line indicates warm phase of ENSO, blue line indicates cold phase of ENSO, green line indicates neutral ENSO conditions. 
$58 \%$, and the probability of two U.S. hurricanes during El Niño lies between $25 \%$ and $31 \%$. Based on the historical data, there is no chance of more than two U.S. hurricanes during El Niño.

The probability of multiple U.S. hurricanes during La Niña is significantly larger (Fig. 2b). The probability of not observing a U.S. hurricane during La Niña ranges from $7 \%$ to $18 \%$. The probability of exactly one La Niña U.S. hurricane lies between $18 \%$ and $31 \%$. The probability of exactly two U.S. hurricanes during La Niña is about $26 \%$, or once in every four cold phase years. For exactly three U.S. hurricanes, the probabilities vary between $15 \%$ and $22 \%$, and for exactly four U.S. hurricanes the range is from $7 \%$ to $15 \%$.

As seen in Figs. $2 a$ and $2 b$, the probability range of exactly one U.S. hurricane is actually higher during warm phase than during cold phase. The probability spread of one U.S. hurricane is the same for both extreme events, however, with both warm and cold phases exhibiting a $90 \%$ confidence interval of $13 \%$ : warm phase from $45 \%$ to $58 \%$, cold phase from $18 \%$ to $31 \%$. For exactly two U.S. hurricanes, the probabilities are about the same between warm and cold events. The range of $90 \%$ confidence is quite narrow during cold phase for exactly two U.S. hurricanes, giving us a high degree of confidence that the probability is close to $26 \%$.

For warm phase, the range of probabilities is larger.

Taking the inverse cumulative frequency distributions of these confidence intervals and comparing the two phases shows the dramatic differences ENSO makes in U.S. hurricane activity (Fig. 2c). For example, the probability range of two or more U.S. hurricanes during El Niño (with $90 \%$ confidence) is $25 \%$ to $31 \%$. For La Niña, the probability for two or more U.S. hurricanes is much greater, ranging from $51 \%$ to $76 \%$.

\section{b. Major U.S. hurricanes}

Major U.S. hurricanes (hurricanes making U.S. landfall with sustained winds of $96 \mathrm{kt}$ or more) are of even more interest due to the larger amount of damage they can produce (Pielke and
Landsea 1998). The impacts of ENSO on major U.S. hurricanes are similar to those for all U.S. hurricanes. There are 63 major U.S. hurricanes in the past 98 years, 5 during El Niño, 37 during neutral conditions, and 22 during La Niña. The mean annual number of major U.S. hurricanes is 0.23 for El Niño, 0.68 for neutral conditions, and 0.95 for La Niña conditions. The number of major U.S. hurricanes per year is shown in Table 4 (Neumann et al. 1993).

Here only empirical data are used to determine return frequencies of major U.S. hurricanes. Figure $2 d$ shows that during an El Niño, the probability of at least one major U.S. hurricane is about $23 \%$. The probabilities for at least one major U.S. hurricane during the other two phases are much higher: $58 \%$ for neutral conditions and $63 \%$ during a cold event. The United States is much more likely to see a major hurricane during neutral or cold events than during El Niño.

During the past 98 years, no El Niño event has ever been associated with more than one major U.S. hurricane. In contrast, the data show there is a $27 \%$ chance of two or more major U.S. hurricanes during cold phase and an $8 \%$ chance during neutral conditions. It is also possible to see three major hurricanes during these phases of the ENSO cycle: $9 \%$ for cold phase, and $2 \%$ for neutral. No year has seen four or more major U.S. hurricanes.
TABLE 4. List of major U.S. hurricanes per year. The column indicates the decade, the row indicates the year.

\begin{tabular}{c|cccccccccc}
\hline \hline Year & $\mathbf{1 9 0 x}$ & $\mathbf{1 9 1 x}$ & $\mathbf{1 9 2} \mathbf{1 9 3 x}$ & $\mathbf{1 9 4 x}$ & $\mathbf{1 9 5} \mathbf{1 9 6 x}$ & $\mathbf{1 9 7 x}$ & $\mathbf{1 9 8 x}$ & $\mathbf{1 9 9 x}$ \\
\hline $\mathbf{0}$ & 1 & 1 & 0 & 0 & 0 & 2 & 1 & 1 & 1 & 0 \\
$\mathbf{2}$ & 0 & 0 & 1 & 0 & 1 & 0 & 1 & 0 & 0 & 0 \\
$\mathbf{3}$ & 0 & 0 & 0 & 1 & 1 & 0 & 0 & 0 & 0 & 1 \\
$\mathbf{4}$ & 0 & 0 & 0 & 3 & 0 & 0 & 0 & 0 & 1 & 1 \\
$\mathbf{5}$ & 0 & 2 & 0 & 1 & 1 & 2 & 1 & 1 & 2 & 1 \\
$\mathbf{6}$ & 2 & 2 & 2 & 1 & 0 & 0 & 0 & 0 & 0 & 1 \\
$\mathbf{7}$ & 0 & 1 & 0 & 0 & 1 & 1 & 1 & 0 & 0 & 0 \\
$\mathbf{8}$ & 0 & 1 & 1 & 1 & 1 & 0 & 0 & 0 & 0 & 1 \\
$\mathbf{9}$ & 3 & 1 & 1 & 0 & 1 & 1 & 1 & 1 & 1 & \\
\hline
\end{tabular}




\section{Conclusions}

Here we quantitatively relate the impacts of warm (and cold) sea surface temperature anomalies in the eastern tropical Pacific Ocean to the number of hurricanes making landfall in the United States. Whether or not an El Niño event is identified during the early summer, as it was in 1997, the potential for a major outbreak of U.S. hurricanes in an El Niño year is significantly decreased. The chance of a major U.S. hurricane is reduced as well.

Acknowledgments. The Center for Ocean-Atmospheric Prediction Studies (COAPS) receives its base support from the Secretary of the Navy grant to James J. O'Brien. Additional support for this work was received from the Office of Global Programs, NOAA. The second author received support from NSF and the Risk Prediction Initiative (RPI).

\section{References}

Draconis, P., and B. Efron, 1983: Computer-intensive methods in statistics. Sci. Amer., 248, 116-130.
Elsner, J. B., and C. P. Schmertmann, 1993: Improving extendedrange seasonal predictions of intense Atlantic hurricane activity. Wea. Forecasting, 8, 345-351.

_ , and A. B. Kara, 1998: Hurricanes of the North Atlantic: Climate and Society. Oxford, in press.

Gray, W. M., 1984: Atlantic seasonal hurricane frequency. Part I: El Niño and $30 \mathrm{mb}$ quasi-biennial oscillation influences. Mon. Wea. Rev., 112, 1649-1668.

Marine Department, Japan Meteorological Agency, 1991: Climate charts of sea surface temperatures of the western North Pacific and the global ocean. $51 \mathrm{pp}$.

Keim, B. D., and J. F. Cruise, 1998: A technique to measure trends in the frequency of discrete random events. J. Climate, 11, 848-855.

Neumann, C. J., B. R. Jarvinen, C. J. McAdie, and J. D. Elms, 1993: Tropical cyclones of the North Atlantic Ocean. Historical Climatology Series 6-2, National Climatic Data Center, 193 pp. [Available from National Climatic Data Center, 151 Patton Ave., Asheville, NC 28801.]

O'Brien, J. J, T. S. Richards, and A. C. Davis, 1996: The effect of El Niño on U.S. landfalling hurricanes. Bull. Amer. Meteor. Soc., 77, 773-774.

Pielke, R. A., Jr., and C. W. Landsea, 1998: Normalized hurricane damages in the United States: 1925-95. Wea. Forecasting, 13, 621-631. 